\title{
jfml
}

Vol 4 (2021), No 2:1-13

DOI: $10.21248 / \mathrm{jfml} .2020 .46$

\section{Co-constructing presence between players and non- players in videogame interactions}

\author{
Introduction to the Special Issue
}

Heike Baldauf-Quilliatre \& Isabel Colón de Carvajal

\section{Co-constructing presence in videogame interactions}

Playing a game (including videogames) is a popular social activity in the everyday life of individuals of all ages, from childhood to adulthood. People play (video)games in different places, on different media, in different situations, alone or with partners, online or offline. It is therefore not surprising that the analysis of games, and especially of videogames, of their users, functions, and roles in society is becoming increasingly important (for an overview, see for instance Egenfeldt-Nielsen et al. 2019; Wildfeuer/Stamenkovic 2020). Gaming is also a place for rich interactions between participants (whether players or non-players) which have been studied from different methodological perspectives (e.g. Lund/Quignard/Shaffer 2017; Reeves/Greiffenhagen/Laurier 2017; Maitland et al. 2018; Zuiker/ Anderson 2019; Ensslin/Finnegan 2019). In these studies, a particular interest has been shown to the construction of presence. In media studies, presence is generally described as "the perceptual illusion of nonmediation" (Lombard/Ditton 1997; see also Lombard/ Jones 2015). In that case, presence is neither limited to gaming nor to new technologies but related to perceptual and psychological immersion.

Corresponding authors:

$\begin{array}{rr}\text { Heike Baldauf-Quilliatre } & \begin{array}{r}\text { Isabel Colón de Carvajal } \\ \text { Université Lyon 2 Lumière, }\end{array} \\ \text { ENS de Lyon, ICAR (UMR } \\ \text { ICARR 5191) } & 5191 \text { ), isabelle.colonde } \\ \text { carvajal@ens-lyon.fr } \\ \text { Postal address: } \\ \text { Ecole Normale Supérieure de Lyon - Site Descartes } \\ \text { Interactions, Corpus, Apprentissages, Représentations (ICAR) } \\ \text { 15, Parvis René Descartes } \\ \text { BP 7000 } \\ 69342 \text { LYON cedex } 07 \text { (France) }\end{array}$


Another approach is proposed by Spagnolli/Gamberini (2002; 2005; 2015): they define presence as a process and argue that, rather than an inner state, presence is a public phenomenon which is constructed through the actions of participants. By throwing a spotlight on actions, Spagnolli/Gamberini raise questions such as "what does it mean to be present in a certain environment? What is the configuration of the environment in which the user is present at a certain moment? What are the pragmatic implications of being present in that environment for the individual and the other copresent individuals?" (Spagnolli/Gamberini 2015: 110; see also Licoppe 2014).

The papers in this special issue are driven by the same type of questions: How do players in the virtual world of Second Life display presence through their avatars and thereby move from gatherings to encounters (Kohonen-Aho/Vatanen)? How do players in Let's Play videos construct tele-presence with their spectators (Schmidt/ Marx)? How do playing and non-playing participants in virtual reality games construct co-presence and therefore create shared play (Olbertz-Siitonen/Piirainen-Marsh/Siitonen)? And how do nonplayers construct different forms of spectatorship by using specific practices of displaying presence (Baldauf-Quilliatre/Colón de Carvajal)?

All the papers focus on the co-construction of presence, analyzing presence as an interactional achievement (and not as an individual and cognitive phenomenon) and focusing on the participants' practices. Following a multimodal conversation analytic approach, they draw on video recordings to show in detail (1) how the participants in these recordings verbally and non-verbally co-construct presence in the specific environment and (2) which resources they use. They mobilize different concepts related to a dynamic, procedural and action-based understanding of presence, such as footing (Goffman 1981), participation (Goodwin/Goodwin 2004) or gathering/encounter (Goffman 1963). Through their analyses, the papers show how co-presence is constructed via dynamic participation frameworks whether the participants are physically co-present (see Olbertz-Siitonen/Piirainen-Marsh/Siitonen and Baldauf-Quilliatre/ Colón de Carvajal) or not (see Kohonen-Aho/Vatanen and Schmidt/ Marx).

To situate the papers within the reflection on spectatorship from an interactional point of view, we will in the following briefly discuss the notions of player and non-player with regard to videogame interactions (section 2) and describe our point of view of a fruitful relationship between media linguistics and conversation analysis (section 3). The last part of this introduction (section 4) presents the four papers of the special issue. 


\section{2 'Players' and 'non-players' in videogame interactions}

In one way or another, all the papers also investigate the role of nonplayers, highlighting the complexity of the participation framework in gaming interactions. However, non-playing is discussed in different ways. Kohonen-Aho/Vatanen are interested in players who, after a short break, use their avatar in the game to display their availability for interaction and for a (new) encounter. Schmidt/Marx focus on the way Let's Play gamers take into account their audience and make their gaming "watchable”. Olbertz-Siitonen/PiirainenMarsh/Siitonen investigate the practices of physically present nonplayers who participate in the gaming activity of a single player. Finally, Baldauf-Quilliatre/Colón de Carvajal also focus on physically present non-players, showing how they simultaneously construct different types of spectatorship and different relationships.

While videogames are sometimes seen as "antisocial", various studies have shown that they can be considered to be a "meeting place around which individuals can gather for the social interaction that is central to group gaming" (Voida/Greenberg 2009: 4). In the words of one of the participants interviewed by Voida/Greenberg: "P11: Everyone's kind of sitting there, everyone's getting along, and it's a common place of interaction" (2009: 4). (Video)gaming thus unites people, even those who are not playing. Spectating and the role of spectators therefore began to attract the attention of game analysts and game developers (Lin/Sun 2011; Kaytoue et al. 2012; Downs et al. 2014). For instance, spectating is investigated from the points of view of general motivations (Sjöblom/Hamari 2017), addiction (Macey/Hamari 2018), and community building (Hamilton et al. 2014). Yet, very little research has been based on naturally occurring interactions and focused on the accomplishment of playing and watching (e.g. Tekin/Reeves 2017). This knowledge gap leads to a simplified understanding of spectating, mostly related to either the individual use of a game or to the spectating of sports events (Ludvigsen/Veerasawmy 2010).

Identifying spectators in videogame interaction is less straightforward than traditional mediated interactions (such as television):

Players not only play (i.e. manipulate controllers and/or move avatars), they may also spend time waiting for their turn, meanwhile observing their co-players (or their avatars in the game). They can temporally be forced out of the game and therefore wait until they can join again. Players can show more or less expertise and as an expert, a player might observe the others' moves in order to evaluate, correct or confirm them. This expertise can be pre-defined (as in teaching situations) or constantly and locally negotiated (as in peer 
interactions). Acting as player thus consists in accomplishing a complex assemblage of different types of temporally fine-tuned activities. Non-playing is therefore neither the counterpart of playing, nor is it automatically associated to spectating: one can be engaged in an interaction with players without being engaged in the gaming activity at all. On the other hand (as shown for instance through Let's play videos), a non-player can be engaged in the gaming (as spectator) without interacting directly with the gamers. So, generally speaking, 'player' and 'non-player' cannot be considered as distinct roles, and 'watching' or 'spectating' cannot be solely associated to non-players. Research on (video)game interactions needs to consider more seriously the different "types" of participants and the complex resulting participation framework. Research also needs to specify what playing, watching and spectating mean, drawing on previous research on other types of spectating (film, television, but also non-screen-based forms such as theater, sports events, exhibitions, museums, etc. ${ }^{1}$ ) or the description of playing in non-gaming situations (assuming that play is not automatically opposed to non-play ${ }^{2}$, but a practice used in different types of situations ${ }^{3}$ ).

In this special issue, we focus on 'non-players' mainly to draw attention to the importance of participants who are, at a particular moment, not accomplishing control actions via technical devices. Despite the problems of the 'non-player' category, it seems a useful and possible concept, at least at this stage of research. Useful, because

- it allows for a parallel between watching videogaming (as spectator) and watching other mediated interactions,

- it questions the complex relationship between activities inside and outside the game, i.e. between the "game" world and the "real" world (see Kohonen-Aho/Vatanen).

Possible, because

- participants draw on different epistemic accesses and authorities for decision making and controlling the game (see OlbertzSiitonen/Piirainen-Marsh/Siitonen),

- in a continuing state of incipient talk, participants build relationships by showing different forms and levels of engagement

1 See for instance Holly/Püschel/Bergmann (2001); Esbjörnsson et al. (2006); Burkhardt (2009); Gerhardt (2014); Albert (2015); Gerwinski/Habscheid/Linz (2018).

2 See Huizinga (1938).

3 See for instance Goffman (1963); Maynard (1991); Tolmie/Rouncefield (2016); Reeves/Greiffenhagen/Laurier (2017). 
in the gaming activity (see Baldauf-Quilliatre/Colón de Carvajal),

- non-players/spectators can be physically and temporally separated from players (see Schmidt/Marx).

The different papers in this special issue show that a 'non-player' category is not only introduced from an analyst-perspective, but also made relevant from the perspective of participants, actively playing (in the sense of controlling the game) or non-playing (in the sense of not controlling the game). In Let's Play videos, the players display their immersion in the game for an audience (Schmidt/Marx). In single-person VR-games (Olbertz-Siitonen/Piirainen-Marsh/Siitonen), the player relies on the other co-present participants as "resources" but maintains epistemic authority. A similar observation is made for other types of games and gaming constellations (Baldauf-Quilliatre/ Colón de Carvajal). And in the world of Second Life, the players display "encounter-readiness", indicating their change of state from a (currently) non-playing participant to a (potentially) playing participant (Kohonen-Aho/Vatanen).

\section{Media linguistics and Conversation Analysis}

Media linguistics investigates the relationship between language use and discourse conveyed through the media in different contexts. It includes the study of traditional mass media (typically, print or broadcast news, but also fictional film and television studies) as well as social and other digital media with the development of computermediated communication (Luginbühl 2015; Perrin 2015; Rabatel 2017). One of the core concepts of media linguistics is the medium and its definition. According to Luginbühl (2015: 16), media linguistics "defines itself through a specific perspective, namely on media as a force co-creating meaning and on cultural linguistic practices".

Conversation Analysis (CA) is an approach developed by sociologist Harvey Sacks in the late 1960s, in close collaboration with Emanuel A. Schegloff and Gail Jefferson, to study the social organization of action in situ (Sacks/Schegloff/Jefferson 1974; Sacks 1992). It is inspired by Garfinkel's ethnomethodology (Garfinkel 1967) and aims to "describe the intertwined construction of practices, actions, activities, and the overall structure of interactions" (cf. Sidnell/ Stivers 2012: 2). One of the main characteristics of CA is its interdisciplinarity: without a deeper knowledge in sociology, linguistics, anthropology, media studies etc., it will not be possible to develop a theory on social interaction (cf. Sidnell/Stivers 2012: 3-4). On the other 
hand, the fine-tuned analysis of interactions, based on (video)recordings, detailed transcriptions and a rigorous methodological approach makes it possible to specify different concepts or observations.

With regard to media linguistics, CA-based studies have enhanced the description of interaction in the media (e.g. Hutchby 2005; Thornborrow/Fitzgerald 2013) as well as interaction with media (e.g. Baldauf-Quilliatre 2012; Giles et al. 2015; Imo 2017). A less developed aspect still seems to be the use of media in interaction ${ }^{4}$ : how are different media (print, radio, television, smartphones, computers, (smart) displays, voice agents, videogames) integrated and used in face-to-face interaction? How do the affordances of the media shape the face-to-face interaction? And what does their use in interaction show about the function of the media? If the description of media-related practices and communication forms from different perspectives (e.g. Holly 2011; Ayass/Gerhardt 2012; Androutsopoulos 2016; Brock/Schildhauer 2017) brings forward the discussion in CA and media linguistics, there are only few studies at the intersection of both disciplines, focusing precisely on this point.

The papers in the special issue aim to contribute to this discussion by exploring the social aspects of videogaming. They draw on media linguistic notions such as presence and immersion as well as the multimodal and sequential analysis of the participants' interaction. They discuss and develop these concepts from an interactional perspective. Simultaneously, the analyses draw attention to specific aspects of gaming as a mediatized practice (Androutsopoulos 2016).

One aspect concerns the role of the avatar. Avatars are frequently considered to be a "hero version of me" (Clark et al. 2018). They do not act on their own, as their actions are the result of the players' controlling actions. Embodying avatars is thus one of the main practices in videogaming. Furthermore, the avatars' actions are perceptible on screen, which allows all participants (players and non-players) to act with regard to them. In this way, embodying avatars fulfills different functions within the participants' interaction.

Another aspect that is highlighted in this special issue concerns the interplay between different types of resources, related to the embodiment of interaction (verbality, vocality, gesture, gaze, etc.), but also to the technological setting, the screen and the affordances of the game. In other words, by accomplishing gaming actions (through avatars), players also interact with other participants inside or outside the game. The papers show how this interplay comes into effect.

4 But see for instance the section of media as part of interaction in Marx/Schmidt (2019) as well as König/Oloff (2019) or DiDomenico/Raclaw/Robles (2020). 
A final aspect concerns engagement in the game. By focusing on non-players, the special issue highlights the fact that engagement in the game goes beyond players' controlling actions (as Human Computer Interaction) or in-game-interaction through avatars, even if they play an important role. Engagement also includes face-to-face interaction with other participants. Our findings thus contribute to a better understanding of gaming itself, more specifically, what doing videogaming means.

\section{Presentation of the papers}

The special issue is composed of four papers drawing on video-recorded videogame interactions in Finnish, German and French.

Laura Kohonen-Aho and Anna Vatanen investigate the transitions from gatherings to encounters in the virtual world of Second Life. Players having completed an individual task "wait" for their coplayers and display their "readiness" to open an encounter. So far, transitions have only been described for face-to-face interaction. Kohonen-Aho and Vatanen show how participants engage in transitions in mediated interactions, especially in computer-mediated communication where the participants interact only via avatars. For instance, they describe virtually embodied pre-beginnings, which are quite different from pre-beginnings in face-to-face interaction. By focusing on avatars and their role in the transition, Kohonen-Aho and Vatanen also contribute to a better understanding of the hybridity (Spagnolli/Gamberini 2002, 2005; Crabtree/Robben 2008; Licoppe 2014) which characterizes technology-mediated interacttions: "real" and "virtual" world can only be considered as intertwined. Their analyses confirm prior research which suggests that gathering and encounter are not $a$ priori two distinctive categories.

Axel Schmidt and Konstanze Marx focus on Let's Play Videos and the co-construction of telepresence by embodying avatars. In contrast to the other papers where all participants or their avatars are physically co-present, Let's Play Videos involve one or several players playing for a physically absent audience. The authors present in detail two practices deployed by the players to share immersion and make the gaming "watchable" for an audience: formulating one's own actions as an "attempt to make intentions accessible" and animating avatars via response cries to "add an emotional dimension". Both are understood as "different but complementary practices of embodying avatars". They investigate immersion and involvement not as cognitive concepts but with regard to their social aspects. Like Kohonen-Aho/Vatanen, the authors are particularly interested in avatars and their embodiment. 
Both papers show that the deep connection between the avatar and its human controller needs to be investigated from a cognitive and interactional point of view.

Margarethe Olbertz-Siitonen, Arja Piirainen-Marsh and Marko Siitonen discuss the social aspect of presence and play in shared virtual reality gameplay. The paper focuses on a setting where only one person is equipped with the VR material and therefore able to perform controlling actions in the game. Based on Larsen/Walter (2019) who describe gameplay as an oscillation between "being-here" and "being-there", they show how this happens and how it is locally negotiated and co-constructed by all participants. The player simultaneously orients to the virtual and the shared physical spaces, while ensuring accountability of his actions in the game. The other physically present participants (non-players / spectators) are not just passive observers, but partially become coplayers - monitoring the player, assisting and contributing to successful gaming. According to the authors, altogether they establish a specific participation framework where presence is "drawn on as a resource as well as negotiated and carefully balanced with respect to access and participation rights". These findings highlight an underspecified aspect of the concept of presence and contribute to a better understanding of spectating in a broader sense.

Heike Baldauf-Quilliatre and Isabel Colón de Carvajal are also interested in physically present non-playing participants. They investigate different settings (with different types of games, different number of participants etc.) and show how players and non-players co-construct the non-players' participation in the gaming activity. The construction of participation is related to the construction of the relationship between the different participants. The authors describe three types of co-constructed relationships: being a couple, being friends and being a supporter. Their findings call for further investigations and further discussions concerning spectatorship and practices of spectating. Similarly to Olbertz-Siitonen/PiirainenMarsh/ Siitonen, the authors characterize spectatorship as emerging, co-constructed and negotiated. Simultaneously, they show how the praxeological context, the physical situation, as well as the affordances of the game influence participation practices and therefore, the participation framework. 


\section{References}

Albert, Saul (2015): Rhythmical coordination of performers and audience in partner dance. Delineating improvised and choreographed interaction. In: Etnografia e ricerca qualitativa $8(3)$, 399-428.

Androutsopoulos, Jannis (2016): Mediatisierte Praktiken: Zur Rekontextualisierung von Anschlusskommunikation in den Sozialen Medien. In: Deppermann, Arnulf/Feilke, Helmuth/Linke, Angelika (Eds.): Sprachliche und kommunikative Praktiken. Berlin, Boston: de Gruyter, 337-367.

Ayass, Ruth/Gerhardt, Cornelia (Hg.) (2012): The appropriation of media in everyday life. Amsterdam, Philadelphia: Benjamins.

Baldauf-Quilliatre, Heike (2012): The construction of audience community via answering machine. The case of the French radio broadcast Lá-bas, sij'y suis. In: Ayass, Ruth/Gerhardt, Cornelia (Eds.): The appropriation of media in everyday life. Amsterdam, Philadelphia: Benjamins, 131-159.

Brock, Alexander/Schildhauer, Peter (Eds.) (2017): Communication Forms and Communicative Practices. New Perspectives on Communication Forms, Affordances, and What Users make of Them. Frankfurt a.M.: Lang.

Clark, Oliver/Grogan, Sarah/Cole, Jennifer (2018): A sort of half-way house, A hero version of me: Men and women's accounts of creating their ideal-self avatar and being portrayed as normative ideal in an exercise videogame. URL: https://psyarxiv.com/6ensp/ [accessed June 25, 2020].

Crabtree, Andy/Rodden, Tom (2008): Hybrid ecologies: understanding cooperative interaction in emerging physical-digital environments. In: Personal and Ubiquitous Computing 12 (7), 481493.

DiDomenico, Stephen/Raclaw, Joshua/Robles, Jessica (2020): Attending to the mobile text summons: Managing multiple communicative activities across physically copresent and technologically mediated interpersonal interactions. In: Communication Research 47 (5), 669-700.

Downs, John et al. (2014): Audience Experience in Social Videogaming: Effects of Turn Expectation and Game Physicality. In: Proceedings of CHI 2014, Toronto, Canada, 3473-3482. URL: https://dl.acm.org/doi/abs/10.1145/2556288.2556965 [accessed June 25, 2020].

Egenfeldt-Nielsen, Simon/Smith, Jonas Heide/Tosca, Susana Pajares (2019): Understanding video games: The essential introduction. New York: Routledge. 
Ensslin, Astrid/Balteiro, Isabel (Hg.) (2019): Approaches to videogame discourse: Lexis, Interaction, textuality. Bloomsbury: Bloomsbury Academic.

Gamberini, Luciano/Spagnolli, Anna (2015): An Action-Based Approach to Presence: Foundations and Methods. In: Lombard, Matthew/Biocca, Frank/Freeman, Jonathan/IJsselsteijn, Wijnand/ Schaevitz, Rachel J. (Hg.): Immersed in Media. Heidelberg et al.: Springer, 101-114.

Garfinkel, Harvey (1967): Studies in ethnomethodology. Cambridge: Polity Press.

Gerhardt, Cornelia (2014): Appropriating live televised football through talk. Leiden: Brill.

Gerwinski, Jan/Habscheid, Stephan/Linz, Erika (2018): Theater im Gespräch: sprachliche Publikumspraktiken in der Theaterpause. Berlin, Boston: de Gruyter.

Giles, David et al. (2015): Micoranalysis of Online Data: The methodological development of "digital CA". In: Discourse, Context and Media 7, 45-51.

Goffman, Erving (1963): Behavior in public places: notes on the social organization of gatherings. New York: Free Press.

Goffman, Erving (1981): Forms of Talk. Philadelphia: University of Pennsylvania Press.

Goodwin, Charles/Goodwin, Marjorie (2004): Participation. In: Duranti, Alessandro (Ed.): A companion to linguistic anthropology. Malden: Blackwell, 224-244.

Hamilton, William/Garretson, Oliver/Kerne, Andruid (2014): Streaming on Twitch: Fostering Participatory Communities of Play within Live Mixed Media. In: Proceedings of CHI 2014, Toronto, Canada, 1315-1324. URL: https://dl.acm.org/doi/abs/1$0.1145 / 2556288.2557048$ [accessed June 25, 2020].

Holly, Werner/Püschel, Ulrich/Bergmann, Jörg (Eds.) (2001): Der sprechende Zuschauer. Wie wir uns Fernsehen kommunikativ aneignen. Opladen: Westdeutscher Verlag.

Holly, Werner (2011): Medien, Kommunikationsformen, Textsortenfamilien. In: Habscheid, Stephan (Eds.): Textsorten, Handlungsmuster, Oberflächen. Berlin, Boston: de Gruyter, 144-163.

Huizinga, Johan (1938): Homo ludens. Boston: Beacon.

Hutchby, Ian (2005): Media talk: Conversation analysis and the study of broadcasting. Berkshire: Open University Press.

Imo, Wolfgang (2017): Interaktionale Linguistik und die qualitative Erforschung computervermittelter Kommunikation. In: Beißwenger, Michael (Ed.): Empirische Erforschung internetbasierter Kommunikation. Berlin, Boston: de Gruyter, 81-108.

Kaytoue, Mehdi/Silva, Arlei/Cerf, Loïc/Meira Jr., Wagner/Raïssi, Chedy (2012): Watch me Playing, I am a Professional: A First 
Study on Video Game Live Streaming. In: Proceedings of $W W W$ 2012, 1181-1188. URL: https://dl.acm.org/doi/10.1145/2187980.2188259 [accessed June 25, 2020].

König, Katharina/Oloff, Florence (Eds.) (2019): Private, Public, and Anonymous Mobile Media Practices. In: Special Issue of Journal for Media Linguistics. URL: https://jfml.org/issue/view/5 [accessed June 25, 2020].

Larsen, Lasse/Walther, Bo (2019): The Ontology of Gameplay: Toward a New Theory. In: Games and Culture. URL: https://doi.org/10.1177/1555412019825929.

Licoppe, Christian (2014): Contested norms of presence. In: Hahn, Kornelia/Stempfhuber, Martin (Eds.): Präsenzen 2.0. Körperinszenierung in Medienkulturen. Berlin: Springer, 97-112.

Lin, Holin/Sun, Chuen-Tsai (2011): The Role of Onlookers in Arcade Gaming: Frame Analysis of Public Behaviours. In: Convergence: The International Journal of Research into New Media Technologies 17 (2), 125-137.

Lombard, Matthew/Ditton, Theresa (1997): At the Heart of It All: The Concept of Presence. In: Journal of Computer-Mediated Communication 3 (2). URL: https://onlinelibrary.wiley.com/doi/full/10.1111/j.1083-6101.1997.tb00072.x [accessed June 25, 2020].

Lombard, Matthew/Jones, Matthew (2015): Defining Presence. In: Lombard, Matthew/Biocca, Frank/Freeman, Jonathan/Ijsselsteijn, Wijnand/ Schaevitz, Rachel J. (Eds.): Immersed in Media. Telepresence Theory, Measurement, and Technology. Heidelberg et al.: Springer, 13-34.

Ludvigsen, Martin/Veerasawmy, Rune (2010): Designing technology for active spectator experiences at sporting events. In: Proceedings of the 22nd Conference of the Computer-Human Interaction Special Interest Group of Australia on Computer-Human Interaction. 96-103. URL: https://dl.acm.org/doi/abs/10.1145/1952222.1952243 [accessed June 25, 2020].

Luginbühl, Martin (2015): Media Linguistics: On Mediality and Culturality. In: 10Plus1 Living Linguistics. 1, 9-26. URL: http://10plus1journal.com/?page_id=177 [accessed June 25, 2020].

Lund, Kristine/Quignard, Matthieu/Shaffer, David (2017): Gaining insight by transforming between temporal representations of human interaction. In: Journal of Learning Analytics 4(3), 102-122. URL: http://dx.doi.org/10.18608/jla.2017.43.6 [accessed June 25, 2020].

Macey, Joseph/Hamari, Juho (2018): Investigating relationships between video gaming, spectating esports, and gambling. In: Computers in Human Behavior 80, 344-353. 
Maitland, Clover et al. (2018): Measuring the capacity of active video games for social interaction: The Social Interaction Potential Assessment tool. In: Computers in Human Behavior 87, 308-316.

Marx, Konstanze/Schmidt, Axel (Eds.) (2019): Interaktion und Medien. Interaktionsanalytische Zugänge zu medienvermittelter Kommunikation. Heidelberg: Winter.

Maynard, Douglas W. (1991): Goffman, Garfinkel, and games. In: Sociological Theory 9.2, 277-279.

Perrin, Daniel (2015): Medienlinguistik. Konstanz: UVK.

Rabatel, Alain (2017): Pour une lecture linguistique et critique des médias: Empathie, étique, pont(s) de vue. Paris: Lambert Lucas.

Reeves, Stuart/Greiffenhagen, Christian/Laurier, Eric (2017): Video Gaming as Practical Accomplishment: Ethnomethodology, Conversation Analysis and Play. In: Topics in Cognitive Science 9 (2), 308-342. DOI: 10.1111/tops.12234.

Sacks, Harvey (1992): Lectures on conversation, Vol. 1 and 2. Edited by G. Jefferson, Oxford: Basil Blackwell.

Sacks, Harvey/Schegloff, Emanuel A./Jefferson, Gail (1974): A simplest systematics for the organization of turn-taking for conversation. In: Language 50, 696-735.

Sidnell, Jack/Stivers, Tanya (Hg.) (2012): The handbook of conversation analysis. Malden, Oxford: Blackwell.

Sjöblom, Max/Hamari, Juho (2017): Why do people watch others play video games? An empirical study on the motivations of Twitch users. In: Computers in human behavior 75, 985-996.

Spagnolli, Anna/Gamberini, Luciano (2002): Immersion/emersion: Presence in hybrid environments. In: Paper presented at the Presence 2002 Fifth Annual International Workshop. Porto, Portugal URL: https://astro.temple.edu/ lombard/ISPR/Proceedings/2002/Spagnolli\%20and\%20Gamberini.pdf [accessed June 25, 2020].

Spagnolli, Anna/Gamberini, Luciano (2005): A Place for Presence. Understanding the Human Involvement in Mediated Interactive Environments. In: PsychNology Journal 3 (1), 6-15.

Tekin, Burak/ Reeves, Stuart (2017): Ways of spectating: Unravelling spectator participation in Kinect play. In: CHI'17 Proceedings of the 2017 CHI Conference on Human Factors in Computing Systems, 1558-1570 DOI: 10.1145/3025453.3025813 [accessed June $25,2020]$.

Thornborrow, Joanna / Fitzgerald, Richard (2013): "Grab a pen and paper": Interaction vs. interactivity in a political radio phone-in. In: Journal of Language and Politics 12 (1), 1-28.

Tolmie, Peter/Rouncefield, Mark (Eds.) (2016): Ethnomethodology at play. New York: Routledge.

Voida, Amy/Greenberg, Saul (2009): Wii all play: the console game as a computational meeting place. In: Proceedings of the SIGCHI 
Conference on Human Factors in Computing Systems, ACM, 1559-1568. DOI: 10.1145/1518701.1518940 [accessed June 25, 2020].

Wildfeuer, Janina/Stamenkovic, Dusan (2020): Multimodale Forschungsperspektiven auf Computerspiele. In: Engelns, Markus/ Voßkamp, Patrick (Hg.): Sprechende Pixel - Computerspielphilologie in Schule und Hochschule. Osnabrücker Beiträge zur Sprachtheorie 96, 7-28.

Zuiker, Steven J./Anderson, Kate T. (2019): Fostering Peer Dialogic Engagement in Science Classrooms with an Educational Videogame. In: Research in Science Education, 1-25. 